\title{
Antarctic fur seal predation on cephalopods at Marion Island
}

\author{
Ryan R. Reisinger $\cdot$ P. J. Nico de Bruyn • \\ Pierre A. Pistorius $\cdot$ Marthán N. Bester
}

Received: 29 July 2009 / Revised: 15 September 2009 / Accepted: 16 September 2009

(C) Springer-Verlag 2009

\begin{abstract}
We report two observations of adult male Antarctic fur seals, Arctocephalus gazella, preying on large octopods at subAntarctic Marion Island during July and August 2008. If Antarctic fur seals take cephalopods opportunistically, as previously suggested, our observations may be a rare event representing such opportunistic predation.
\end{abstract}

Keywords Otariid · Arctocephalus gazella . Diet ·

Octopus magnificus · SubAntarctic islands .

Opportunistic feeding

Antarctic fur seals, Arctocephalus gazella, breed mainly on islands south of the Antarctic Polar Front (APF), but also breed north of the APF at Macquarie Island (Goldsworthy 1999), Iles Crozet (Guinet et al. 1994) and Marion and Prince Edward Islands (Condy 1978). Their feeding ecology has been investigated at a number of localities throughout the Southern Ocean and studies of diet have primarily been based on stomach or scat sampling methods, the former based on stomach contents from shot animals (Croxall and Pilcher 1984). Recently, stable isotope and fatty acid analyses have further elucidated their dietary intake (e.g., Lea et al. 2002; Cherel et al. 2007). The opportunistic feeding behaviour of the species is evidenced by the variety of prey species consumed (e.g., Makhado et al.

R. R. Reisinger $(\varangle) \cdot$ P. J. N. de Bruyn · M. N. Bester

Mammal Research Institute,

Department of Zoology and Entomology,

University of Pretoria, Pretoria 0002, South Africa

e-mail: rrreisinger@zoology.up.ac.za

P. A. Pistorius

Department of Zoology,

Nelson Mandela Metropolitan University,

PO Box 77000, Port Elizabeth 6031, South Africa
2008), the variation in the composition of prey throughout their range (e.g., Daneri and Coria 1992; Cherel et al. 1997; Klages and Bester 1998) and their occasional inclusion of extraordinary prey items in their diet (e.g., king penguins, Hofmeyr and Bester 1993).

At Marion Island (Fig. 1), their diet was investigated by Condy (1981), Klages and Bester (1998) and Makhado et al. (2008). Based on scat samples, myctophid fish species predominate in the diet of A. gazella at Marion Island, with cephalopods generally contributing negligibly. Most cephalopods were not identified, but Brachioteuthis risei and Octopus magnificus were recorded (Klages and Bester 1998; Makhado et al. 2008). This dietary preference, including that of krill, appears to be common in various populations of the species (Reid 1995; Reid and Arnould 1996; Cherel et al. 1997; Casaux et al. 1998; Daneri et al. 1999) and it could be that these prey items are selectively targeted irrespective of cephalopod availability (Kirkman et al. 2000). However, at some sites, the importance of cephalopods in the diet is known to increase during autumn and winter (Heard Island, Green et al. 1991; South Orkney Islands, Daneri and Coria 1992).

During $249 \mathrm{~h}$ of observation (2-3 h per observation session, 93 sessions between May 2008 and April 2009), we observed and photographed (Fig. 2) two similar cases of A. gazella preying on large octopods at Van den Boogaard Beach, Marion Island (Fig. 1; 46 $54^{\prime} \mathrm{S}, 37^{\circ} 45^{\prime} \mathrm{E}$ ). The observations took place on 21 July and 14 August 2008, at 14:37 and 11:09 GMT +3 , respectively. On both occasions, conditions were overcast and relatively wind still (Beaufort Sea State 2). The observations were made from the same point on a low headland approximately $4 \mathrm{~m}$ high. In both cases, adult male A. gazella were first noticed at the water's surface, holding a prey item in their jaws and vigorously shaking it from side to side. In both cases, the prey was 
Fig. 1 Map of Marion Island showing the localities where A. gazella were observed preying on cephalopods

Fig. 2 Series of photographs depicting an adult male A. gazella consuming a large octopod at Van den Boogaard Beach, Marion Island. Figure 1c shows the seal vigorously shaking the octopod
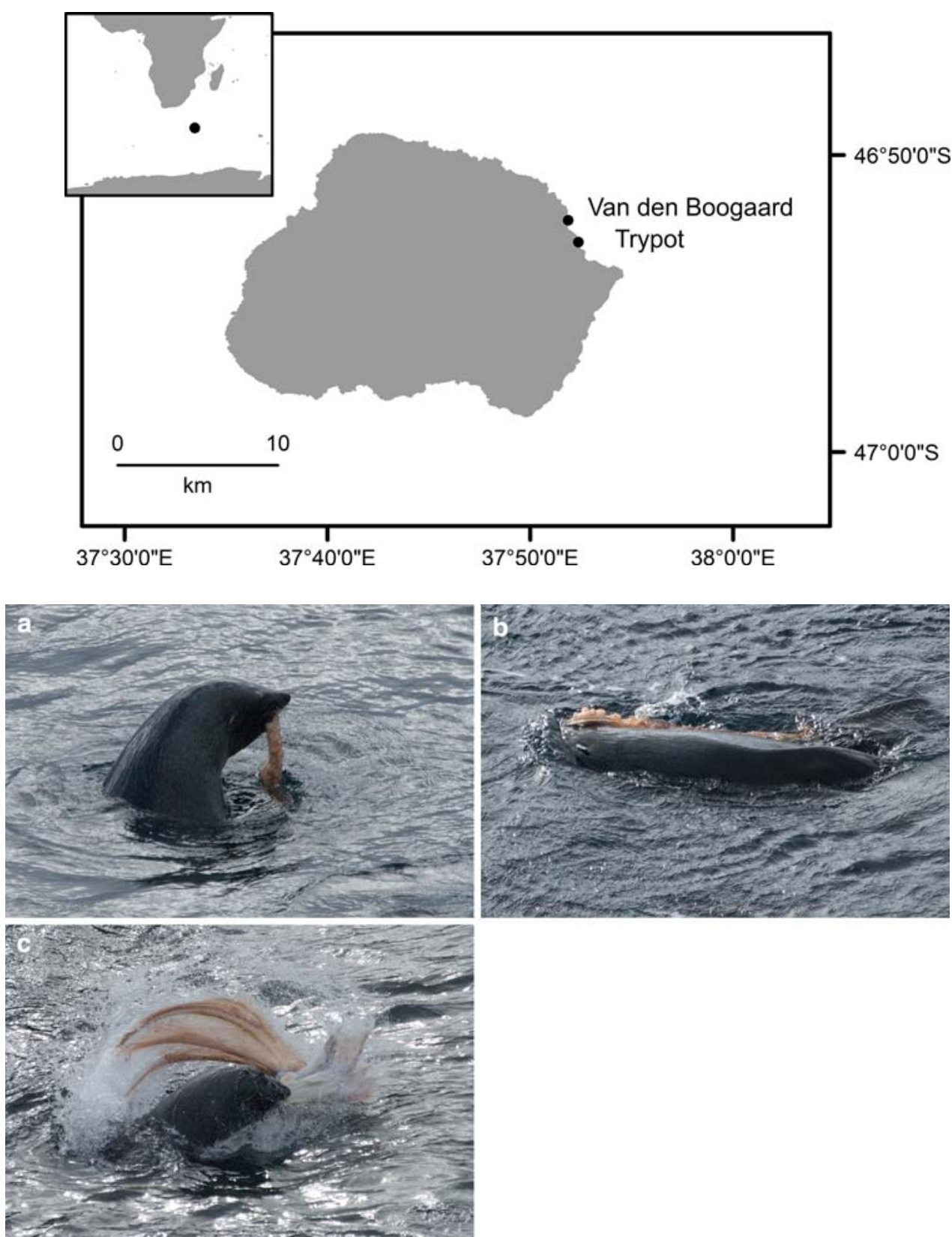

identified as a large octopod, possibly $O$. magnificus (Villanueva et al. 1991), with tentacles approximately $1 \mathrm{~m}$ in length (Fig. 2b). The seals vigorously shook the octopod bodies to tear pieces off (Fig. 2c), or flung the entire body through the air, and slowly swam after such pieces. In both cases, the seals remained between approximately 4 and $30 \mathrm{~m}$ from shore and the incidents lasted approximately 5 and $10 \mathrm{~min}$, respectively. Both seals were seen consuming parts of the prey, although no estimate was made of the proportion eaten. Some parts remained at the water surface and giant petrels (Macronectes spp.) fed on these. On both occasions 1-2 other adult male A. gazella were in the immediate vicinity and slowly swam after pieces of the carcasses, although there were no obvious interactions between the seals. These observations represent direct evidence for consumption of large octopods by this seal species at Marion Island. During February 1997, a sub-adult male A. gazella was seen dragging an unidentified squid species approximately $1 \mathrm{~m}$ in length onto Trypot Beach, Marion Island (PAP, personal observation).

Bonner and Hunter (1982) and du Toit et al. (2004) describe very similar feeding behaviour in A. gazella and Cape fur seals, A. pusillus pusillus, feeding on seabirds, and suggest that predation on seabirds may be an extension of play behaviour. In our observations, both seals were likely only tearing a large prey item into more manageable pieces, rather than playing with the prey. They consumed some proportion of the octopods and did not interrupt feeding to 
play with other seals, as described by Bonner and Hunter (1982).

The description of cephalopods in otariid diets, from scat and stomach samples are well known to include biases (e.g., Lipinski and David 1990; Staniland 2002; de Bruyn et al. 2003; Gudmundson et al. 2006). The differential erosion and passage rates of hard items in relation to their size, result in considerable variation in samples obtained from different methods (e.g., Gudmundson et al. 2006), and among individuals (Staniland 2002). Importantly, large items (such as the beaks of large O. magnificus) are unlikely to appear in an animal's scat if ingested. For example, in their study of the cephalopod diet of A. pusillus pusillus based on scat analysis, de Bruyn et al. (2005) found that $O$. magnificus consumed were markedly smaller than mean published values for freshly captured specimens of the species-possibly reflecting a bias against the passage of large beaks, rather than the real prey size distribution. Indeed, using stomach sample analyses, Lipinski and David (1990) showed that large cephalopod beaks are retained in the stomach and probably regurgitated, thereby introducing bias in description of prey size in the diet when using scat analyses. A. pusillus pusillus, New Zealand fur seals, A. forsteri, and northern fur seals, Callorhinus ursinus, are known to eject squid beaks orally (Rand 1959; Tate 1981; Gudmundson et al. 2006) but no evidence has been presented that A. gazella selectively eject hard parts (Kirkman et al. 2000).

Antarctic fur seals do opportunistically take cephalopods as prey (this study) as previously suggested (e.g., Kirkman et al. 2000), however, the frequency of such occurrences are unknown and our sightings may merely be a rare event representing such opportunistic predation. If such occurrences are indeed uncommon, then biases inherent to cephalopod detection in scat analysis would not skew resultant dietary analyses.

Acknowledgments We thank the South African Department of Environmental Affairs for providing logistical support within the South African National Antarctic Programme, and the Department of Science and Technology (administered through the National Research Foundation) for funding the marine mammal monitoring programme at Marion Island.

\section{References}

Bonner WN, Hunter S (1982) Predatory interactions between Antarctic fur seals, macaroni penguins and giant petrels. Br Antarct Surv Bull 56:75-79

Casaux R, Baron A, Carlini A (1998) The diet of the Antarctic fur seal Arctocephalus gazella at Harmony Point, Nelson Island, South Shetland Islands. Polar Biol 20:424-428

Cherel Y, Guinet C, Tremblay Y (1997) Fish prey of Antarctic fur seals Arctocephalus gazella at lle de Croy, Kerguelen. Polar Biol 17:87-90
Cherel Y, Hobson KA, Guinet C, Vanpe C (2007) Stable isotopes document seasonal changes in trophic niches and winter foraging individual specialization in diving predators from the Southern Ocean. J Anim Ecol 76:826-836

Condy PR (1978) Distribution, abundance and annual cycle of fur seals (Arctocephalus spp.) on the Prince Edward Islands. S Afr J Wildl Res 8:159-168

Condy PR (1981) Annual food consumption, and seasonal fluctuations in biomass of seals at Marion Island. Mammalia 45:21-30

Croxall JP, Pilcher MN (1984) Characteristics of krill Euphausia superba eaten by Antarctic fur seals Arctocephalus gazella at South Georgia. Br Antarct Surv Bull 63:117-125

Daneri GA, Coria NR (1992) The diet of Antarctic fur seals, Arctocephalus gazella, during the summer-autumn period at Mossman Peninsula, Laurie Island (South Orkneys). Polar Biol 11:565-566

Daneri GA, Piatkowski U, Coria NR, Carlini AR (1999) Predation on cephalopods by Antarctic fur seals, Arctocephaulus gazella at two localities of the Scotia Arc, Antarctica. Polar Biol 21:59-63

De Bruyn PJN, Bester MN, Mecenero S, Kirkman SP, Roux J-P, Klages NTW (2003) Temporal variation of cephalopods in the diet of Cape fur seals in Namibia. S Afr J Wildl Res 33:83-96

De Bruyn PJN, Bester MN, Kirkman SP, Mecenero S, Roux JP, Klages NTW (2005) Cephalopod diet of the Cape fur seal, Arctocephalus pusillus pusillus, along the Namibian coast: variation due to location. Afr Zool 40:261-270

Du Toit M, Bartlett PA, Bester MN, Roux JP (2004) Seabird predation by individual seals at Ichaboe Island, Namibia. S Afr J Wildl Res 34:45-54

Goldsworthy SD (1999) Maternal attendance behaviour of sympatrically breeding Antarctic and subantarctic fur seals, Arctocephalus spp., at Macquarie Island. Polar Biol 21:316-325

Green K, Williams R, Burton HR (1991) The diet of Antarctic fur seals during the late autumn and early winter around Heard Island. Antarct Sci 3:359-361

Gudmundson CJ, Zeppelin TK, Ream RR (2006) Application of two methods for determining diet of northern fur seals (Callorhinus ursinus). Fishery Bull 104:445-455

Guinet C, Jouventin P, Georges JY (1994) Long-term population changes of fur seals Arctocephalus gazella and Arctocephalus tropicalis on subantarctic (Crozet) and subtropical (St Paul and Amsterdam) islands and their possible relationship to El Niño southern oscillation. Antarct Sci 6:473-478

Hofmeyr GJG, Bester MN (1993) Predation on king penguins by Antarctic fur seals. S Afr J Antarct Res 23:71-74

Kirkman SP, Wilson W, Klages NTW, Bester MN, Isaksen K (2000) Diet and estimated food consumption of Antarctic fur seals at Bouvetøya during summer. Polar Biol 23:745-752

Klages NTW, Bester MN (1998) Fish prey of fur seals Arctocephalus spp. at subantarctic Marion Island. Mar Biol 131:559-566

Lea MA, Cherel Y, Guinet C, Nichols PD (2002) Antarctic fur seals foraging in the Polar Frontal Zone: inter-annual shifts in diet as shown from fecal and fatty acid analyses. Mar Ecol Prog Ser 245:281-297

Lipinski MR, David JHM (1990) Cephalopods in the diet of the South African fur seal (Arctocephalus pusillus pusillus). J Zool 221:359-374

Makhado AB, Bester MN, Kirkman SP, Pistorius PA, Ferguson JWH, Klages NTW (2008) Prey of the Antarctic fur seal Arctocephalus gazella at Marion Island. Polar Biol 31:575-581

Rand RW (1959) The Cape fur seal (Arctocephalus pusillus). Distribution, abundance, and feeding habits off the south western coast of the Cape Province. S Afr Div Sea Fish Invest Rep 34:1-75

Reid K (1995) The diet of Antarctic fur seals (Arctocephalus gazella Peters 1875) during winter at South Georgia. Antarct Sci 7:241-249 
Reid K, Arnould PY (1996) The diet of Antarctic fur seals Arctocephalus gazella during the breeding season at South Georgia. Polar Biol 16:105-114

Staniland IJ (2002) Investigating the biases in the use of hard prey remains to identify diet composition using Antarctic fur seals (Arctocephalus gazella) in captive feeding trials. Mar Mamm Sci $18: 223-243$
Tate ML (1981) The autumn-winter diet of the New Zealand fur seal Arctocephalus forsteri (Lesson) with special reference to its cephalopod prey. University of Otago, Dunedin

Villanueva R, Sanchez P, Roeleveld MAC (1991) Octopus magnificus (Cephalopoda: Octopodidae), a new species of large octopod from the southeastern Atlantic. B Mar Sci 49:39-56 